\title{
Social optimal shifts and fares for the Barcelona taxi sector.
}

\author{
Josep Maria Salanova Grau*a ${ }^{\mathrm{a}}$, Miquel Estrada ${ }^{\mathrm{b}}$ \\ ${ }^{\mathrm{a} C e n t r e ~ f o r ~ R e s e a r c h ~ a n d ~ T e c h n o l o g y ~ H e l l a s ~(C E R T H) ~-~ H e l l e n i c ~ I n s t i t u t e ~ o f ~ T r a n s p o r t ~(H I T), ~}$ \\ Thessaloniki 57001, Greece. Telephone: 00302310498433. Fax: 00302310498269
}

${ }^{\mathrm{b}}$ Center for Innovation in Transport (CENIT), Barcelona Tech, Technical University of Catalonia (UPC), C/Jordi Girona 29 2A, Barcelona 08034, Spain. Telephone:0034934137667. Fax:0034934137675

jose@certh.gr,miquel.estrada@upc.edu

* Corresponding author

\begin{abstract}
This paper applies a mathematical model for supporting the decision and policy making in the city of Barcelona, presenting the key performance indicators of the Barcelona taxi market, which are waiting/access time and benefits of the drivers. The model accounts for demand elasticity, which allows for estimating the optimum fare level and estimating the related demand for taxi services, which allows the taxi decision makers to have a rough estimation of the taxi sector turn over. In addition, the model is applied to a full-day time period, allowing for useful insights on the duration and distribution of the taxi shifts that should be defined by the taxi policy makers as well as the optimal operation mode for each interval of the day. Finally, the model implementation in the city of Barcelona determines that the optimum fares for the taxi sector is 0.68 euros/kilometer and the optimum number of taxis is 19 taxis/ $/ \mathrm{km}^{2}$. In this situation, the most effective taxi policy is to have 4 days with an 8 -hour shift and one day with two non-consecutive 4-hour shifts every week.
\end{abstract}

Keywords: Taxi modeling, taxi policy, transport on demand, Barcelona

\section{Introduction to taxi policy regulation and deregulation}

Historically, most of the taxi markets have been regulated. Restrictions on taxi market entry have been applied by many cities around the world. The first city that restricted the number of taxis was New York City in 1937, while nowadays most of the cities regulate the number of vehicles providing taxi services. Traditionally, this regulation was applied for protecting the drivers and the customers, but most of the times it was applied without analyzing the taxi market itself before deciding how to regulate the service. When this kind of decisions are taken without studying and analyzing the actual situation, or having an implementation plan, both entry restrictions and fare regulations may affect significantly the taxi sector, leading to important welfare losses. As a result of this, the price of the licenses in markets where taxi licenses are tradable are very high (e. g. Paris $€ 125,000$, Sydney $\$ 300,000$, Melbourne \$500,000, New York \$600,000 (OECD 2007)). In these cases, as revealed in various studies, they are rising up constantly due to the exploitation of their owners. Reforms have often been opposed to reduce the incomes of drivers, which are normally low, and restrictive conditions have been applied in this direction, but there is no evidence that taxi incomes are higher in markets with regulated entry conditions. License owners are benefited by these measures and not the drivers. One example is Melbourne, where taxi licenses were valuated at approximately $\$ 500,000$, but drivers' income is estimated at $\$ 8-\$ 14$ per hour (OECD 2007). Regulation has been extensively discussed concluding mainly on the statement that regulation of entry and fares must not act simultaneously; deregulation of access to the taxi market must be implemented in most cities, which will increase the supply and the level of service of customers. Entry deregulation must be accompanied by new regulations, such as fare regulation and special regulations on high-demand generation points, such as airports, train stations or hotels.

Many cities are deregulating their taxi markets due to the negative consequences of regulation (bad level of service, low salaries for drivers, fare abuses, lack of innovation). Deregulation has most of the times positive impacts, and nowadays many cities have removed entry restrictions, resulting in lower waiting times, increased customer satisfaction and fare reduction. Salanova et al. (2011) present detailed impact of deregulation. In relation to fares, deregulation is very difficult to implement due to the fact that customers must have the possibility of comparing 
prices, which means that the customers should know the price of the service prior to hail the taxi (not feasible) or choose a taxi in the stand market (opposed to the FIFO rules). Market liberalization is an interesting challenge, but in cities where high supply restrictions have been applied, there may be a strong opposition to reform proposals from the license-owners. Oppositely, the taxi market can be subsidized in order to better match offer and demand (Tong et al. 2015).

Arguments support that license-owners must be compensated in case of deregulation: one approach first used in Ireland is to give the additional licenses to each license-owner, ensuring that the new monopoly will remain in their hands; alternatively the new license can be given to taxi drivers without taxi license. Another example can be found in Melbourne, where a 12 year program is adding to the stock of licenses a number of licenses equal to the yearly demand growth. On the other side, externalities such as congestion or pollution should be taken into account when increasing the number of vehicles. The above highlight the necessity of developing modeling tools for decision makers, which will use them for evaluating the impact of the policies applied to the taxi market. Salanova et al. (2011) presents an overview of these models. From the taxi modeling perspective, the most significant contributions to the taxi policy making can be found in Douglas (1972), Foerster and Gilbert (1979), Schaller B. (1995), Yang et al. (2005), Schaller B. (2007), Cetin and Eryigit (2011) and Cetin and Eryigit (2013). However, most of the conclusions drawn in these contributions were based on the results of regulation measures that did not consider the economic effects on both taxi drivers and users. In Salanova (2013), a cost minimization model is presented to define the optimal regulation variables considering the taxi sector cost as well as the impacts on the user travel time. This model is able to identify the optimal set of decision variables (fleet size, taxi fare) that minimizes the total system cost (users and taxi drivers). The theoretical framework in which this based is based is condensed and presented in Salanova and Estrada (2016).

The aim of this paper is to implement the econometric model to the city of Barcelona and obtain useful insights that can be considered for the decision makers for defining the taxi policy. The main results are from the planning perspective the definition of the optimum number of taxis and fee as well as the resulting demand from these values, while from the operation perspective the main results are the number of taxis needed at each time of the day and the optimum shifts distribution for providing this supply level while maintaining acceptable working conditions for the drivers.

The paper is organized as follows: the state of practice regarding taxi policy making is presented in the second section; the third section deals with the application of the proposed methodology to the Barcelona taxi sector using real-world data and concluding in useful conclusions on the most effective taxi policy that should be applied. Finally, section four presents the conclusions of the above analyses.

\section{State of art and practice}

The main discussion related to the selection of taxi fares and fleet size is related to choosing the first best solution or the second best solution. The first best solution is related to the minimum unitary cost (social optimum) and has been proposed by Cairns and Liston-Heyes, 1996, Arnott, 1996, Yang et al., 2002, Fernandez et al., 2006 and Chang and Chu, 2009, while the second best solution aims at ensuring no losses (or zero-benefit) to the taxi drivers and has been proposed by Cairns and Liston-Heyes, 1996, Yang et al., 2002, Fernandez et al., 2006 and Chang and Chu, 2009. Regulation is proposed in order to achieve one of the two solutions, mainly regulating the number of licenses and the operation mode and/or the taxi fares.

\subsection{Operation modes}

The three most common operation modes in most cities are dispatching, hailing and stand. Schaller (2007) presents an interesting classification of cities based on the composition of their taxi markets identifying three main markets:

- Mostly taxi services provided through dispatching centers with a few (if any) taxi services provided at taxi stands or hailing taxis in the streets(e. g. Montgomery). Usual entry policies are related to company-level standards with and without limit on the number of cabs.

- Mix of mostly dispatching and taxi stand services with few hailing trips (e. g. San Francisco). Usual entry policies are related to company-level entry qualifications combined with limits on the number of cabs granted or totally closed entry markets with strong geographic restrictions. 
- Combination of taxi stand and hailing trips (e. g. New York). Usual entry policies related to the limitation on the number of cabs, usually adjusted to the change in the trips volume.

Schaller (2007) concludes that there is a strong need for numerical control in hailing and stand markets, and a relatively relaxed entry control in dispatching markets. Table 1 shows the market composition of the cities analyzed by Schaller together with their population, area and density. As seen, dispatching and cab stand markets predominate in cities with lower density. As density is growing, the percentage of cab stands is growing, while hailing markets predominate only in cities with a high density.

Table 1 Data from the cities represented by Schaller (2007)

\begin{tabular}{|l|l|l|l|c|c|c|}
\hline \multirow{2}{*}{ City } & & & & \multicolumn{3}{|l|}{$\begin{array}{l}\text { Market composition estimated by the authors based on the visual } \\
\text { representation of Schaller (2007) }\end{array}$} \\
\cline { 6 - 8 } & Population & Area & Density & Street Hail & Cab stand & Dispatch \\
\hline Montgomery & 201.998 & 404 & 500 & Inexistent & Inexistent & Dominant \\
\hline Dallas & 1.254 .236 & 887 & 1.414 & Inexistent & Dominant & Coexistent \\
\hline San Diego & 1.359 .132 & 840 & 1.618 & Inexistent & Coexistent & Dominant \\
\hline San Jose & 964.695 & 452 & 2.134 & Inexistent & Coexistent & Dominant \\
\hline Brookline & 58.732 & 18 & 3.318 & Inexistent & Inexistent & Dominant \\
\hline Boston & 645.169 & 125 & 5.144 & Inexistent & Coexistent & Coexistent \\
\hline San Francisco & 808.976 & 121 & 6.686 & Coexistent & Coexistent & Coexistent \\
\hline New York city & 8.175 .133 & 789 & 10.356 & Dominant & Inexistent & Inexistent \\
\hline
\end{tabular}

\subsection{Regulation}

Most of the cities in the world have regulated taxi markets, controlling the number of vehicles circulating in the streets and/or the respective applied fares. There are various methods applied in the U. S. cities to set the number of taxi licenses. Two of them are described below:

- Freezing the number of taxis in operation at the moment the decision is made (arbitrary measure). Adopted in Boston, Chicago, New York and other major cities during the 1930s.

- Periodic reviews of the Public Convenience and Necessity (PCN) of increasing the number of taxis.

There are economic and non-economic arguments in favor of entry control in taxi markets. The economic argument is basically the social welfare achievable with entry control, avoiding market failures. Non-economic arguments are potentially cross-modal competition, congestion and pollution issues. Moore \& Balaker (2006) declared recently that most of the economic opinions favor open entry to the taxi industry. CENIT (2004) identifies arguments in favor and against fare control, presented in Table 2.

Table 2 Arguments in favor and against fare control. Source: own elaboration from CENIT (2004)

\begin{tabular}{|l|l|l|}
\hline Arguments & Against free fares & Against fare control \\
\hline $\begin{array}{l}\text { Operational } \\
\text { arguments }\end{array}$ & $\begin{array}{l}\text { No feasible in the hailing and stand } \\
\text { markets }\end{array}$ & $\begin{array}{l}\text { Free market will give better solutions to each } \\
\text { operation mode }\end{array}$ \\
\hline Consumer protection & Higher fares in low demand zones & $\begin{array}{l}\text { Uncertainty fixing the right fares } \\
\text { No fare abuses }\end{array}$ \\
\hline Competitiveness & & Car renting has no regulation \\
\hline
\end{tabular}

The main consequences of regulated markets are the increase of the prices and the reduction of the number of licenses. Various examples are presented below:

- In Brisbane (Australia), the number of taxis per 10,000 inhabitants decreased from 19.8 in 1960 to 9.8 in 1999.

- In Melbourne (Australia), the corresponding number declined from 12.3 in 1951 to 9.6 in 1995. In the same city, price of the license has increased by $76 \%$ in the period 1989-2004, due to the near-zero releases of new licenses by the regulator. 
- In Dublin, the price of licenses increased by 25 in the 20 years prior to the deregulation of the Irish taxi industry.

- In New York, the number of taxi medallions is almost 1.400 fewer than in 1937. Prices in 2000 were 250,000 \$, in 2005 had reached 379,000 \$, and 600,000 \$ in 2007.

- In Hong Kong, medallions have increased from 200,000 HK\$ in 1980 to 1.500,000 HK\$ in 1987.

A relation of regulation status in various cities as well as more deregulation consequences can be found in Salanova et al. (2011).

\section{Case study: the city of Barcelona}

The econometric model used in this paper is based on the original model presented in detail in Salanova (2013) accounting for the users' costs, the drivers' benefits (seen as a negative cost) as well as the externalities generated by the taxis with the modifications proposed by Salanova and Estrada (2016) including elastic demand, 24h demand profile and shifts policy. More details related to the formulations used in the model are presented in Salanova et al. (2014), where the authors present a review of various formulations developed for the estimation of the variable of the taxi market.

Barcelona is the city that presents the second highest population density in Europe. The number of taxi vehicles in the Barcelona Metropolitan Area is 10.482 while the number of active taxi license holders is 11.076, from which a $33 \%$ is related to one of the 24 dispatching centers of the city. The total number of daily trips is 225.000 ; the number of stops dedicated to the taxi services is 272 with a total capacity of more than 1.700 vehicles in the city. The city of Barcelona concentrates more or less the $80 \%$ of the taxi services. This means that the current supply and demand is respectively $\lambda_{\mathrm{d}}=22 \mathrm{veh} / \mathrm{km}^{2}-\mathrm{h}$ and $\lambda_{\mathrm{u}}=60 \mathrm{trips} / \mathrm{km}^{2}-\mathrm{h}$ (year 2013). The average waiting time during the years 2004 and 2009 was $2-6 \mathrm{~min}$, the average distance $5-6 \mathrm{~km}$, the average time $12-14$ minutes and the average cost $7-10$ euros (Salanova 2013). The service tariff is regulated by IMET (the regulation body of the taxi sector in Barcelona), with both temporal and distance-based fare, but in order to simplify the model only the kilometric charge is used in the aggregated model (the average fare is $\tau=0.67 € / \mathrm{km}$ ).

The taxi sector in the city of Barcelona presents three operational modes: hailing, stand and dispatching, although the vast majority of taxis operated mostly in hailing mode before 2005. However, the economic crisis forced that taxis argued the deployment of more taxi stands by the City Council. It would help taxi owners to reduce the operating cost (fuel, maintenance) while the vehicle is vacant. From this time on, the number of taxi stands has grown significantly. However, the provision of on-street taxi stands is made at the expenses of using the public space for other purposes (freight distribution, car parking slots, etc.). In addition to that, the explosion of new application for smart phones has increased the number of trips in the dispatching sector, promoting a promising operating mode. Therefore, the municipality of Barcelona must decide which is the most beneficial operating mode and the fleet size for the city considering the effects on the taxi sector, users and society. Based on this selection, it would promote the usage of each mode and deploy the auxiliary infrastructure to make them more useful. This question is addressed in Section 3.2.

The average cost of the taxi trip in Barcelona has increased significantly since 2004, but at the same time the number of daily trips per driver has been reduced. The characteristics of the trips (duration and length) have remained more or less the same, with a small increase in the trip length during the last years. Five periods can be recognized between 2004 and 2012 in Figure 1:

- 2004-2005: increase in the number of daily trips per driver and the trip cost, which means more income for the drivers, increase of the daily working time and distance of the drivers.

- 2005-2008: decrease of the number of daily trips and their length, increase in the trip cost. Drivers reduce the variable costs but reduce the idle distance while maintaining the working hours.

- 2008-2009: decrease of the number of daily trips but small increase in their length, increase in the trip cost.

- 2009-2010: stable number of daily trips and significant increase in their length, increase in the trip cost. Increase in the total distance, significant increase of the working hours together with a reduction of the idle distance, the drivers wait at taxi stands. Small increase in the working hours. 
- 2010-2012: decrease of the number of daily trips but small increase in their length, increase in the trip cost. Reduction of the working hours and significant increase in the idle distance, which means significant reduction of the income per kilometer. The total distance remains stable.

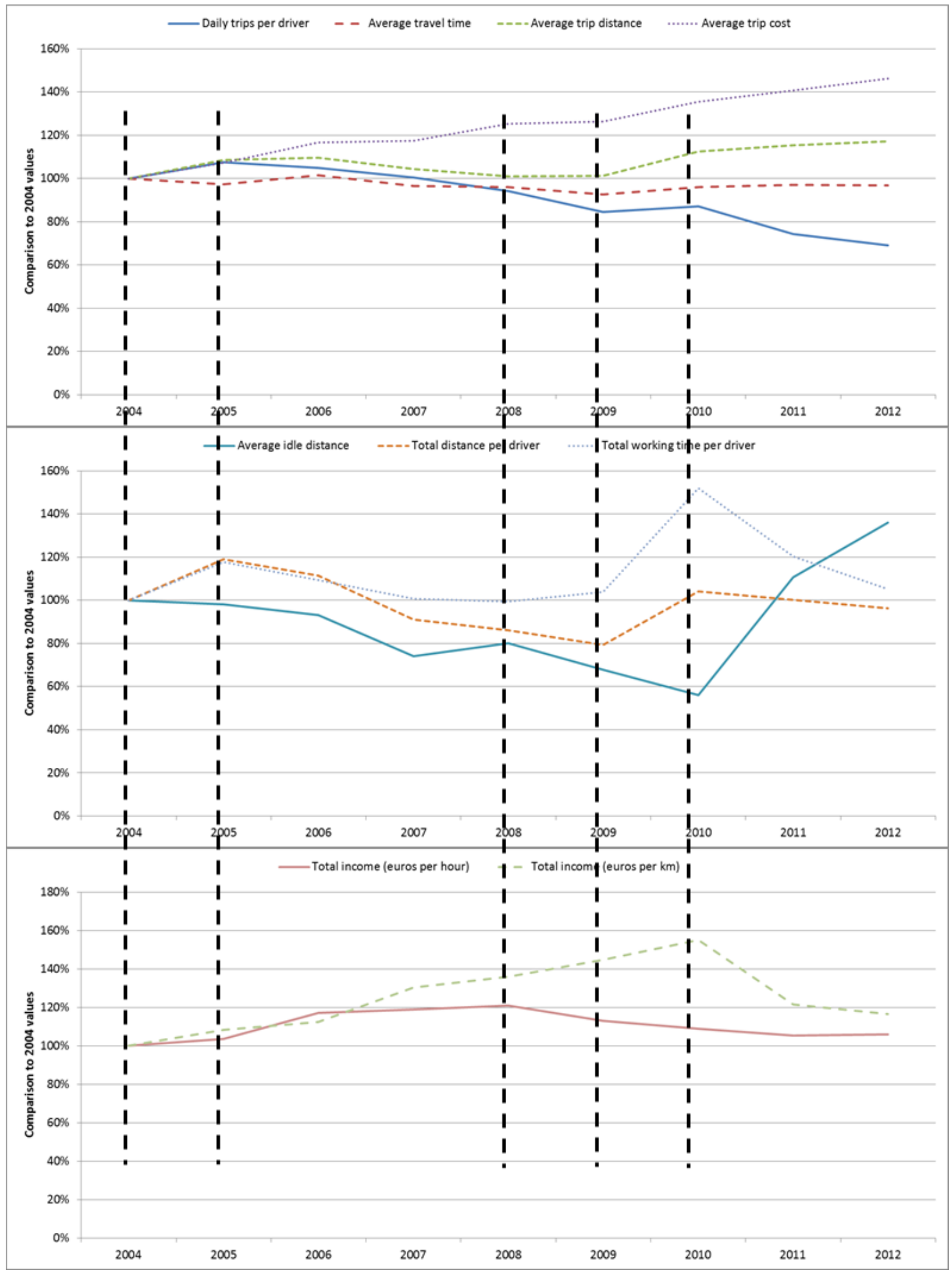

Figure 1 Evaluation of the most significant performance indicators of the taxi market in Barcelona 
The current regulation of taxis in Barcelona only restricts the maximum number of taxis (frozen from 2005) while the number of license holders was not constrained. In fact, the $28 \%$ of vehicles were operated in year 2013 in double shift (Cenit, 2014), that is, the vehicle had two or more drivers along the day, increasing the working hours per day of each vehicle. Therefore, IMET has been forced to increase the fares to guarantee a minimal profitability for taxi owners. However, this fact leads to a vicious circle: the fares should continue being increased as more vehicles will operate in double shift. In order to break this tendency, a new regulation of taxi shifts (vehicle oriented) is needed, determining the maximal number of taxis in service at each time of the day, which is addressed in Section 3.3.

\subsection{Results of the dispatching market application}

The econometric model presented in Salanova (2013) is solved applying elastic demand for various fleet sizes and fees, obtaining the demand for taxi trips for each pair of values (number of taxis and applied fare). Equation (1) estimates the expected demand as a function of fares, service supply and waiting time. Based on this relationship, the effects of this service provision and demand estimation on the user cost and taxi driver benefit can be made by Equations (2) and (3) respectively.

where,

$$
\lambda_{u}=\widetilde{\lambda_{u}} \cdot e^{-\gamma\left(\alpha_{W} \cdot T_{W}+\frac{D+\overline{\mathrm{d}} \cdot \tau_{k m}}{V o T_{u}}\right)}
$$

$\widetilde{\lambda_{\mathrm{u}}}$ is the maximum demand for taxi trips

$\gamma$ is the scaling parameter

$\alpha_{\mathrm{W}}$ is the customer perception factor of the waiting time

$\mathrm{T}_{\mathrm{W}}$ is the waiting time of customers ( $\mathrm{min}$ ) calculated as in Salanova and Estrada (2015)

$\mathrm{D}$ is the flag-drop charge $(€)$

$\overline{\mathrm{d}}$ is the average distance of the trip $(\mathrm{km})$

$\tau_{\mathrm{km}}$ is the taxi fee per unit of distance $(€ / \mathrm{km})$

$\mathrm{VoT}_{\mathrm{u}}$ is the value of time of the taxi customers $(€ / \mathrm{min})$

where,

$$
Z_{u}=\lambda_{u} \cdot A \cdot\left[\alpha_{A} \cdot T_{A}+\alpha_{W} \cdot T_{W}+\alpha_{I V} \cdot T_{I V}+\frac{D+\overline{\mathrm{d}} \cdot \tau_{k m}}{V o T_{u}}\right]
$$

$\lambda_{u}$ is the hourly demand for taxi trips (trips per hour and area of service)

$\mathrm{A}$ is the area of the region $\left(\mathrm{km}^{2}\right)$

$\alpha_{A}$ is the customer perception factor of the access time

$\alpha_{I V}$ is the customer perception factor of the in-vehicle time

$T_{A}$ is the access time of customers ( $\mathrm{min}$ )

$T_{I V}$ is the in-vehicle time of customers (min)

$$
Z_{d}=\frac{\lambda_{d} \cdot A}{V o T_{d}}\left[-\frac{\lambda_{u}}{\lambda_{d}} \cdot \frac{D+\overline{\mathrm{d}} \cdot \tau_{k m}}{V o T_{u}}+\left(\frac{\lambda_{u}}{\lambda_{d}} \cdot \bar{d} \cdot C_{k m}+C_{h}\right)\right]
$$

where,

$\lambda_{\mathrm{d}}$ is the taxi hourly supply (vehicles per hour and area of service)

VoT $_{d}$ is the value of time of the taxi drivers $(€ / \mathrm{min})$

$\mathrm{C}_{\mathrm{km}}$ is the operational cost per unit of distance of taxis $(€ / \mathrm{km})$

$\mathrm{C}_{\mathrm{h}}$ is the hourly operational cost of the moving taxis $(€ / \mathrm{min})$

The fact that the demand depends on the waiting time and vice versa is solved by formulating a bi-level optimization problem where the optimum fleet is calculated at the upper level (minimizing the unitary system costs) and the related waiting time and demand are calculated at the lower level. Details on how the bi-level problem is solved and its convergence are presented in Salanova and Estrada (2016).

Figures 2, 3 and 4 present the results of the application of the bi-level problem, which is solved by enumerating the fees and number of taxis and forming a grid with the combinations of the enumerations. Figure 2 presents the demand level for each combination or supply and fare while figure 3 presents the drivers quantitative benefit (income minus expenses) and customers qualitative performance (LoS) for the same metrics. Finally, Figure 4 presents the social welfare as a combination of the drivers benefit and the customers' performance. 


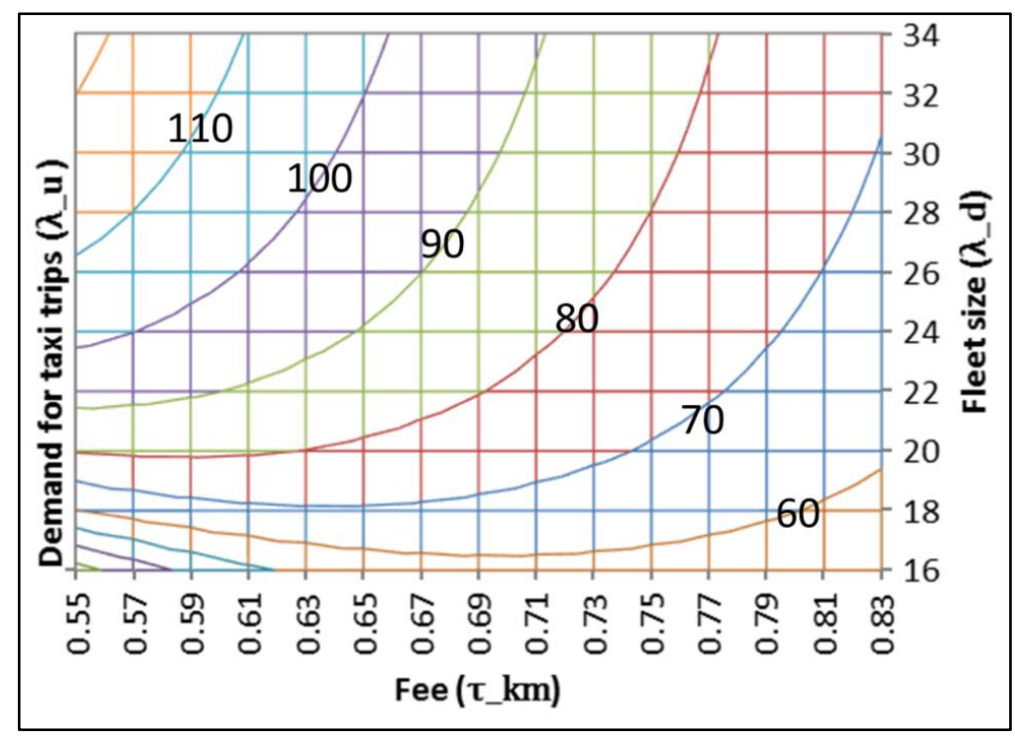

Figure 2 Effect of fares and fleet size on demand for taxi trips

Two regions can be observed in Figure 2, which presents the demand for taxi trips $\left(\lambda_{u}-\mathrm{Z}\right.$ axis) for each combination of fare (X axis) and fleet size $\left(\lambda_{d}-Y\right.$ axis). One region is identified where the number of taxis is very low and the demand does not depend significantly on the fare (between 16 and 22 taxis per $\mathrm{km}^{2}$ and hour). The second region represents a large taxi density where the demand highly depends on the fare (between 22 and 34 taxis per $\mathrm{km}^{2}$ and hour). These results can be used by the taxi regulation decision maker for estimating the income of the taxi sector by multiplying the demand ( $\mathrm{Z}$ axis) for taxi trips and the trip cost, obtained from the multiplication of the fare (X axis) and the average distance. In addition, having the income of the sector and the number of taxis ( $\mathrm{Y}$ axis), the income of the taxi drivers can be estimated as the ratio between the income sector and the number of taxis. With this data, the decision maker will be able to better define the regulations of the taxi sector taking into account all the involved actors.

The same analysis can be conducted for the drivers' benefit, the consumer surplus and the social welfare.
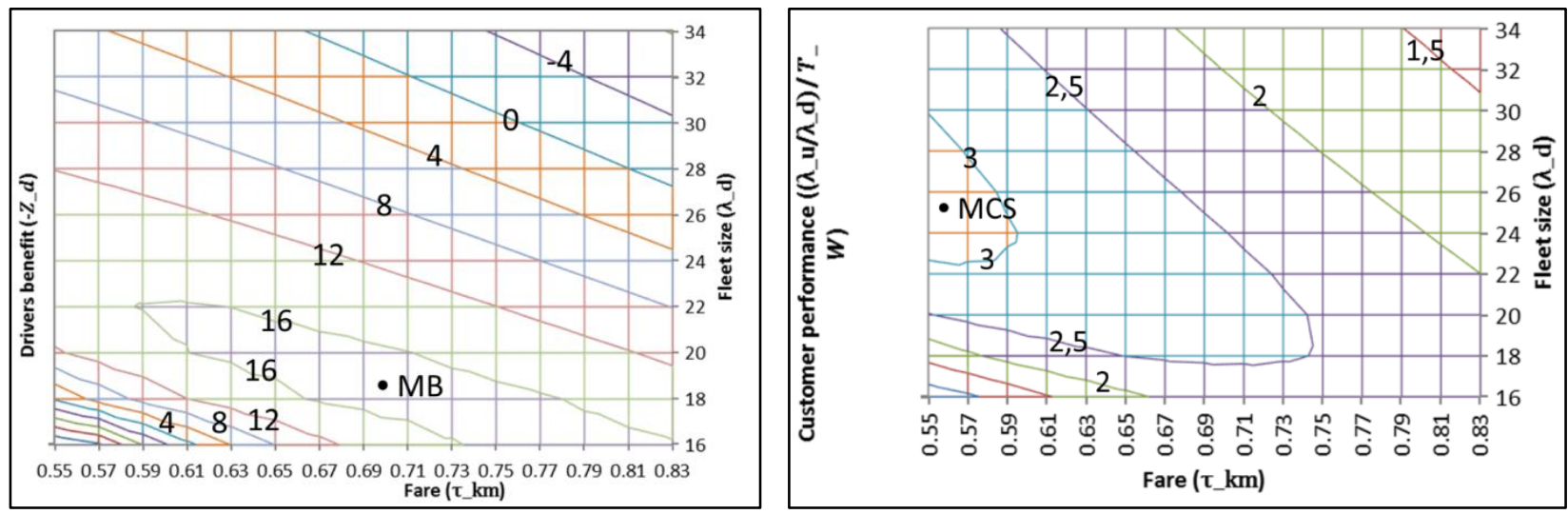

Figure 3 Effect of fares and fleet size on drivers' benefit (left) and on consumer surplus (right)

The maximum benefit (MB) for the drivers is obtained with a low number of taxis and high fees, which can be related to a provision of high-quality services to a demand sector with high economic possibilities. Oppositely, the maximum consumer surplus (MCS), which is calculated as the ratio between the trips per vehicle and the waiting time, is obtained with large fleets and low fares as depicted in Figure 3. 
Combining the consumers'surplus and the producers's surplus, the social welfare is obtained where the optimum region (MSW) is defined between MCS and MB.

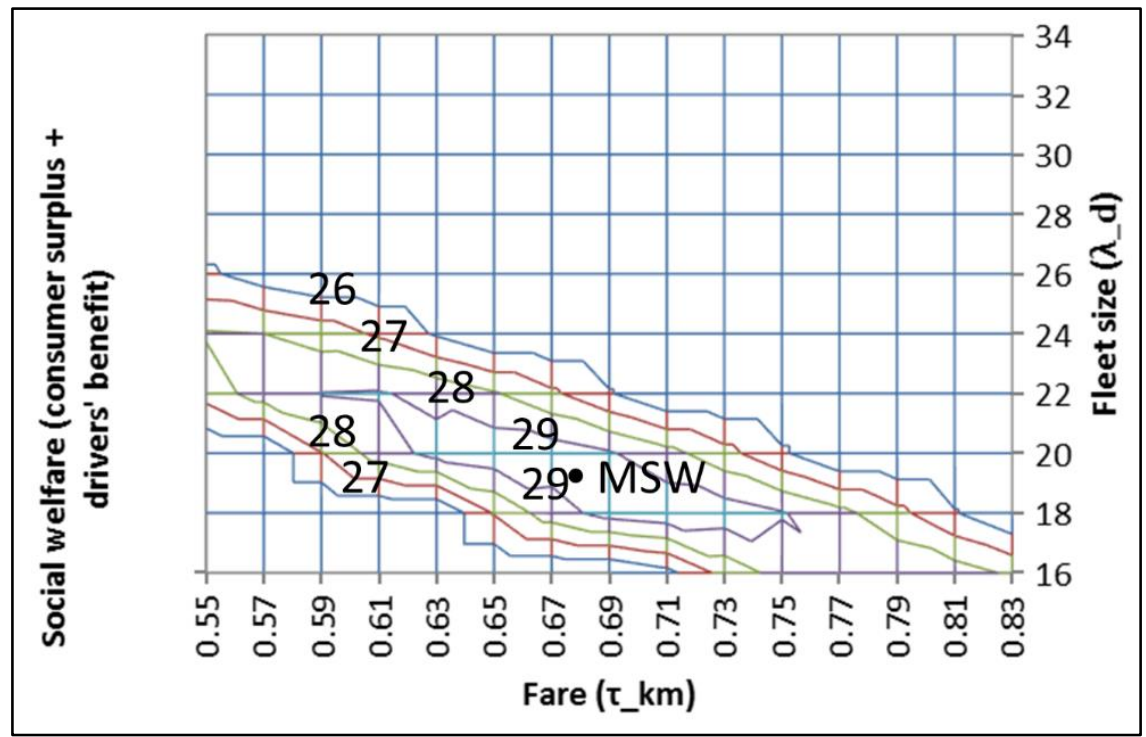

Figure 4 Effect of fares and fleet size on social welfare

From the above figures it can be concluded that the optimum number of taxis per hour and square kilometer is between 16 (optimum for the drivers) and 26 (optimum for the users), while at system level the optimum value is between 19 and 20. Regarding fares, the optimum charge should be between 0.55 euros (optimum for the users) and 0.77 euros-km(optimum for the drivers); while, at system level, the optimum value is between 0.67 and 0.69 . The decision variables for the social optimal solution will vary in these ranges depending on the ratios between the VoT and the exploitation costs.

The real number of taxis in operation $\left(22\right.$ taxis $\left./ \mathrm{km}^{2}-\mathrm{h}\right)$ is between the optimum values for the users and the drivers and very near to the optimum value, while the fare obtained by the model is significantly lower than the real one $(1.07 € / \mathrm{km} ; 0.88 € / \mathrm{km}$ without VAT). As a result, the current supply of taxis in year 2013 is greater than the optimal value provided by the econometric model. The variation between optimal and current metrics is justified by the current double shift practice. There is no regulation about the maximal number of hours that one vehicle can operate. Therefore, fares should be higher than the optimal values in order to compensate the oversupply and guarantee a minimal income for taxi owners.

\subsection{Optimum supply for taxi services in Barcelona}

The model is applied to the three operation modes (hailing, stand and dispatching) obtaining the optimum supply for each one following the formulation found in Salanova (2013) and Salanova and Estrada (2016).

At this point the demand is considered inelastic in order to obtain comparable results for the three operation modes (the use of an elastic demand will not allow for comparing the results of the different modes since the number of users will vary with the level of service). The operation mode with the minimum optimum number of taxis is the hailing mode, due to the impact of the externalities of the circulating taxis, while the operation mode with the maximum optimum number of taxis is the stand mode. The maximum number of taxis with non-negative profits (second best) is very similar for the three operation modes. Finally, the stand mode presents the highest losses, since the first best and the second best have the largest difference, while in the dispatching mode the difference is lower. There are no losses in the hailing market, since the inclusion of the externalities has reduced the optimum number of taxis below the second best value. The losses are calculated as the amount of money that taxi drivers lose if the number of taxis is equal to the social optimum including the taxi driver salary as well as all fix and variable costs. It can also be seen as the amount of money that should be provided to drivers per trip in order to provide the waiting times to customers of the first best solution. 
All the above is related to the peak hour, which means that, for different hours, the results can vary significantly. In order to obtain results for supporting decision makers in a real city, the model should be applied to the 24 hourly intervals of the day and analyze the variation of the different parameters during the whole day. It can be the case that the three operation models are optimum for different periods of the day, mostly depending on the demand and congestion levels. Therefore, the three models have been applied to 24 hourly demand levels in order to acquire a better understanding of the provision of services during the day. The demand level is presented in Figure 5 together with the optimal fleet size obtained for each operation mode. It should be noted that the hypothesis for the stand model of homogeneous distribution of stops within the whole area together with the high walking cost for the users creates the necessity for a large number of stops and therefore for a large number of taxis waiting at these stops (in order to guarantee zero waiting time for the customers, which is one of the hypothesis of the model presented by Salanova (2013)), thus reducing the access time of users, but increasing the unitary cost due to the loss for the taxi drivers.

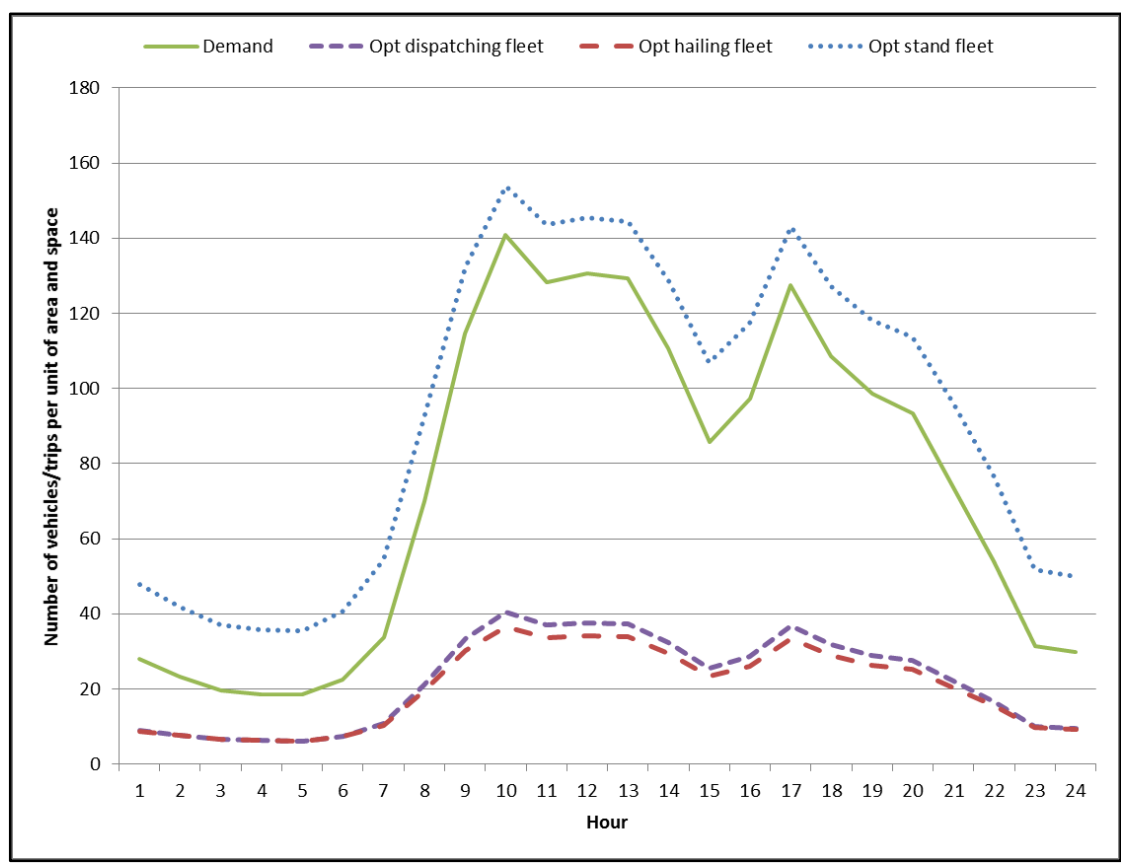

Figure 5 Demand and optimum fleet for each operation mode along the day

The waiting (dispatching and hailing modes) or access time (stand mode), the unitary costs and the benefit of the drivers are presented in Figure 6.

The access times of the stand mode are significantly lower than waiting times of the dispatching and the hailing modes, but this is because the number of taxis in the stand mode is significantly higher. At the same time, the waiting/access time at night are higher than during the day, but the increase is different for each operation mode, being the hailing mode the one which presents the highest impact of the low demand levels at night. It is interesting to highlight that the unitary system costs are very similar during the day, but at night the hailing mode presents a higher unitary costs due to the low demand and unproductive vehicle-kilometers. The benefit of the drivers is similar for both the hailing and the dispatching modes, while the stand mode presents the lowest benefits, especially at night. Due to the walking constraints the stand solution requires a high number of taxi stands, which are served by a fleet 4 times larger than in the other two modes (as it can be observed in figure 5), so the benefits of the taxi drivers are negative. This would mean that a subsidy to the taxi sector should be provided in order to be able to serve the demand for taxi trips, which has no sense. In order to apply the stand model a specific analyze of the demand should be done in order to identify the areas with higher demand, and then decide if taxi stands are needed by applying the model to smaller areas. In the same direction, if the stand model results to be optimal during some intervals of the day (somewhere between peak and off-peak intervals in concrete zones), the decision maker can define a multiuse stand model, where the stops may be sued during the peak hours for freight delivery, during off peak hours for meeting point between taxis and taxi customers, and finally for parking private vehicles at night. 


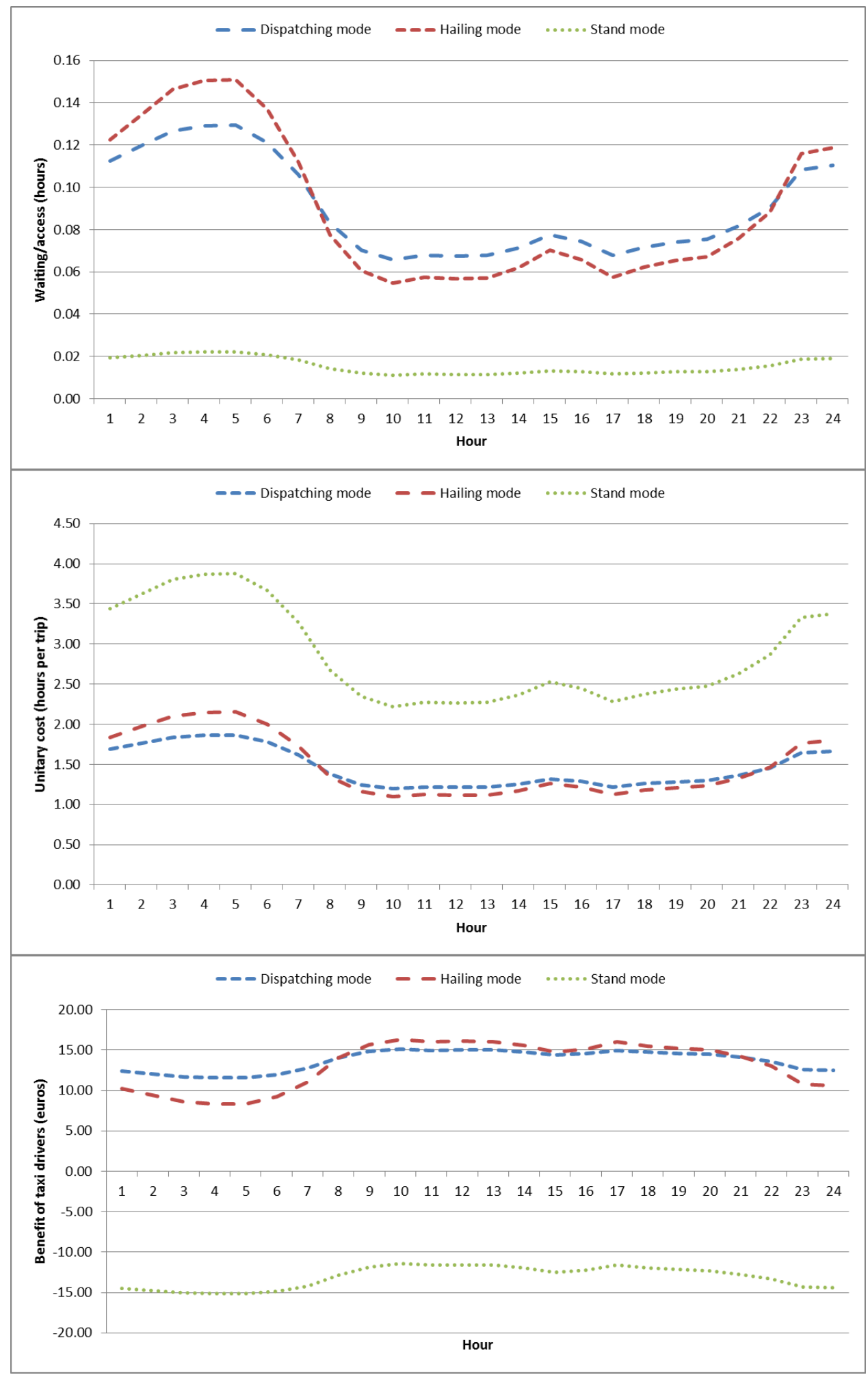

Figure 6 Waiting/access time - unitary cost - benefit of taxi drivers for each operation mode along the day

From the above results, it can be defined that different operation modes are optimum during the day, so the decision maker could regulate the operation modes by time of day. In Barcelona, the dispatching mode has smaller unitary 
cost when the demand level is lower (between 23:00 and 08:00), while the hailing mode has smaller unitary cost the rest of the day, when the demand level is higher. This difference in the unitary cost is composed by less waiting time for the users and more benefits for the drivers and is presented in Table 3.

Table 3. Waiting time - benefit of taxi drivers - unitary cost for hailing and dispatching modes along the day,

\begin{tabular}{|c|c|c|c|c|c|c|}
\hline & \multicolumn{3}{|c|}{$23: 00-07: 00$} & \multicolumn{3}{c|}{$08: 00-22: 00$} \\
\cline { 2 - 7 } & Hailing & Dispatching & Difference & Hailing & Dispatching & Difference \\
\hline Waiting time (hours) & $0.12-0.15$ & $\mathbf{0 . 1 1}-\mathbf{0 . 1 3}$ & $9 \%-13 \%$ & $\mathbf{0 . 0 6}-\mathbf{0 . 1 0}$ & $0.07-0.10$ & $14 \%$ \\
\hline Benefit of taxi drivers (euros) & $8-10$ & $\mathbf{1 2}$ & $16 \%-33 \%$ & $\mathbf{1 5}$ & 15.5 & $3 \%$ \\
\hline Unitary cost (hours per trip) & $1.8-2.25$ & $\mathbf{1 . 6}-\mathbf{1 . 7 5}$ & $11 \%-22 \%$ & $\mathbf{1 . 1}$ & 1.2 & $9 \%$ \\
\hline
\end{tabular}

\subsection{Optimum taxi shifts policy in Barcelona}

The above models provide the optimum number of vehicle-hours to be offered during each hour of the day at strategic level. This value should be obtained at operational level by applying the correct shifts policy to the taxi market. The city of Barcelona has recently analyzed a new policy for regulating the working hours during the day, and not only the working days during the week. These shifts can have various durations, from 2 to 8 hours.

Three scenarios have been tested in order to define the best policy of regulating the working hours of one vehicle in a day of service. The supply level used is the one obtained by the dispatching model, but the methodology is valid for the other operation modes by changing the optimum supply levels:

- Scenario A. One shift of eight hours

- Scenario B. Two shifts of four hours

- Scenario C. Four shifts of two hours

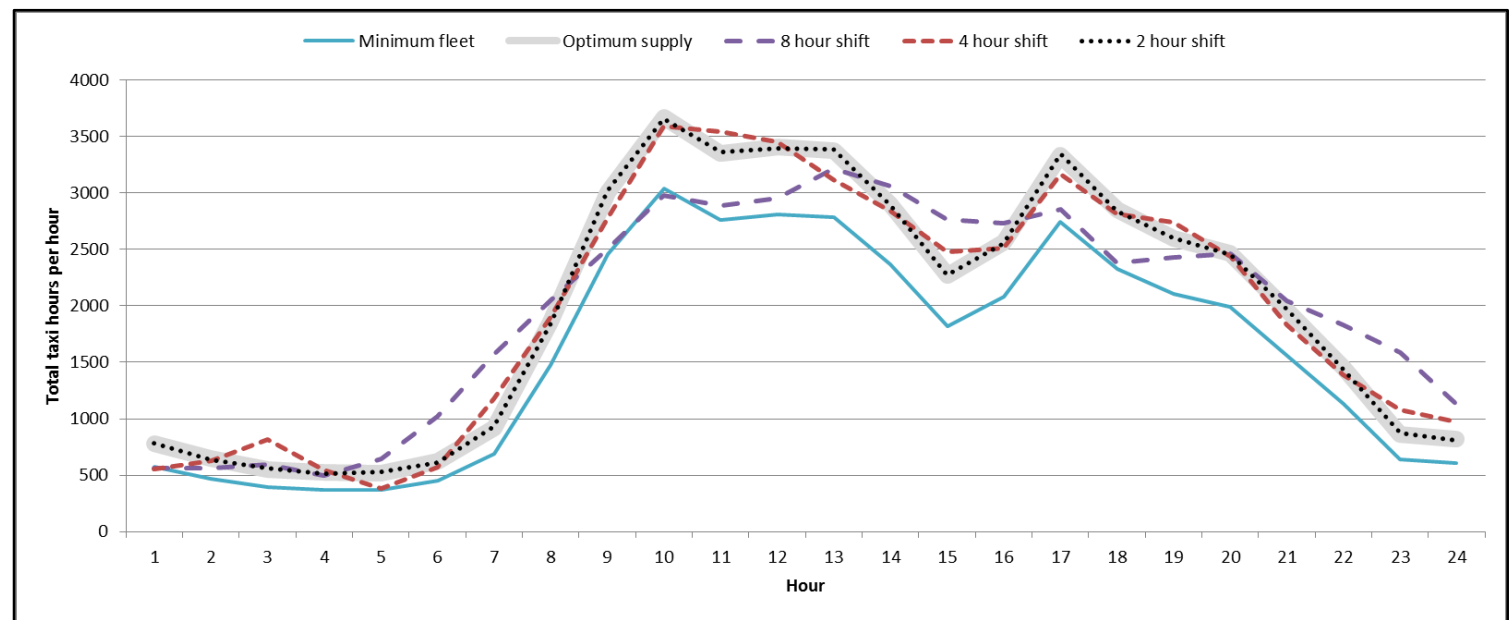

Figure 7 Taxi-hours provided by the three policy scenarios in comparison to the optimum fleet size

The 2-hour shift and the optimum supply curves almost coincide, which means that the optimum supply level can be achieved by 2-hour shifts. Smaller shifts allow a better fit of the provided taxi-hours to the optimum values (as expected). The areas between each line and the optimum value represent the over or under supply, which is related to lower income for taxi drivers and higher waiting time for taxi customers respectively. This area goes from 7,000 hours in the 8 -hour shift to 275 hours in the 2-hour shift.

Table 2. Taxi shifts scenarios

\begin{tabular}{|l|l|l|l|}
\hline & Working hours in a day & $\begin{array}{l}\text { Difference with regard to the optimal } \\
\text { shift proposal }\end{array}$ & \% of oversupply veh-hours \\
\hline Scenario A & 47,296 & 7,439 & $15,7 \%$ \\
\hline Scenario B & 47,296 & 3,081 & $6,5 \%$ \\
\hline Scenario C & 47,296 & 275 & $0.6 \%$ \\
\hline
\end{tabular}


The impact of each policy on the most significant indicators of the taxi market is presented in Figure 8.

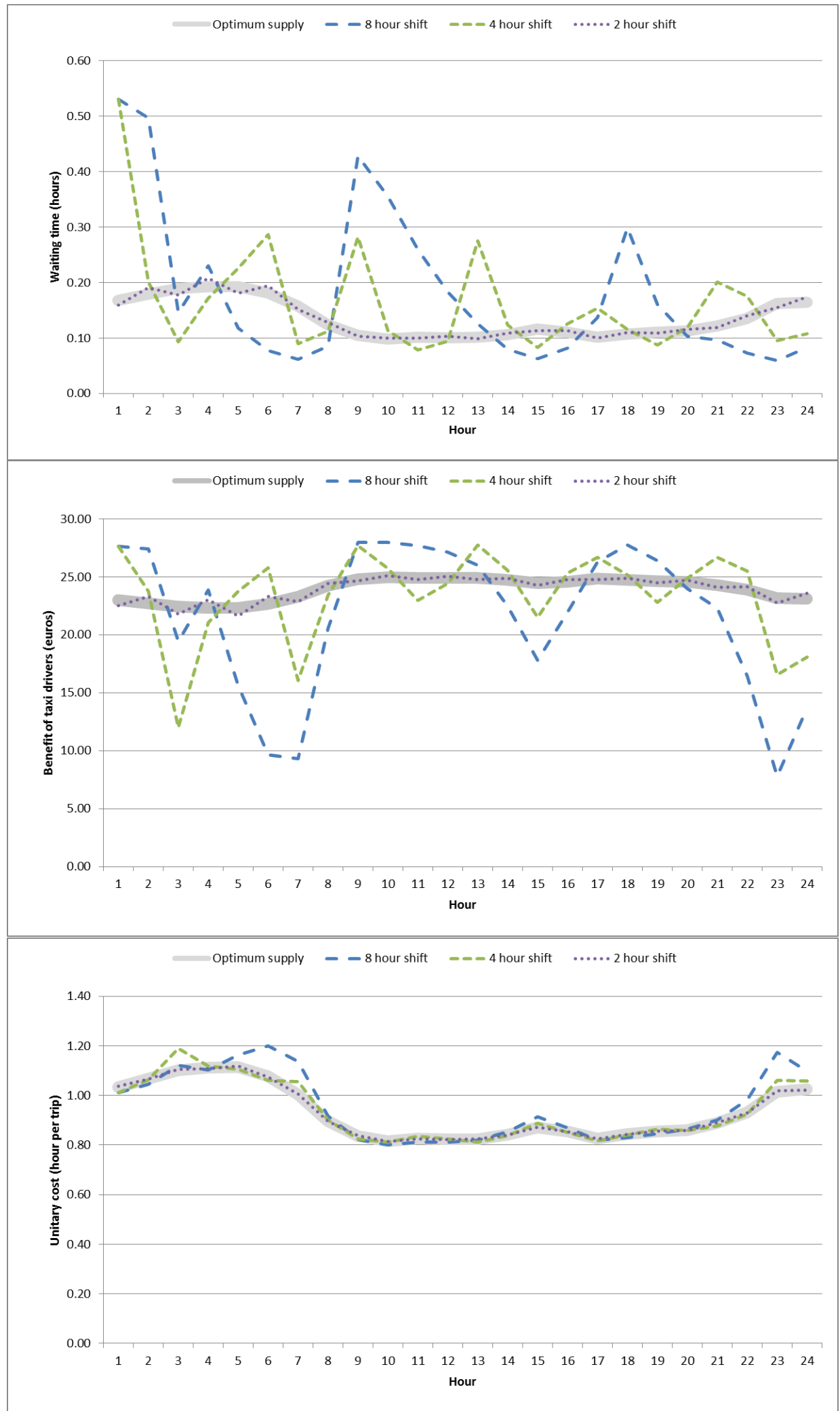

Figure 8 Customer waiting time, income and unitary cost for the various proposed policies 
The waiting time variation in relation to the optimum waiting time depends on the difference between the optimum and the real number of taxi-hours offered. When the benefits of the taxi drivers are higher than the ones of the optimum supply levels, the waiting time of customers is higher, and oppositely, when the benefits of taxi drivers are lower than the expected, the waiting time of customers are lower. It is interesting to highlight that the benefit of the optimum taxi-hour supplied is equal during the day, which means that the benefit of each working hour is similar, providing equity to the taxi drivers independently of the interval of the shifts assigned. Oppositely, the benefits obtained by the 4-hour or the 8-hour shift have important variations along the day, which means that the shifts should be assigned taking into account equity issues related to the benefit of each working hour. Amat (2010) estimated the hourly income for the taxi driver in Barcelona between 16.23 and 18.34 euros with an average of 17.45 euros, which is in line with Figure 9. The variation of the unitary costs is smoother due to the compensation effect between the increase/decrease of the waiting time of customers and the respective decrease/increase benefits of drivers. It is interesting to analyze the accumulated over/under-offered hours during the day.

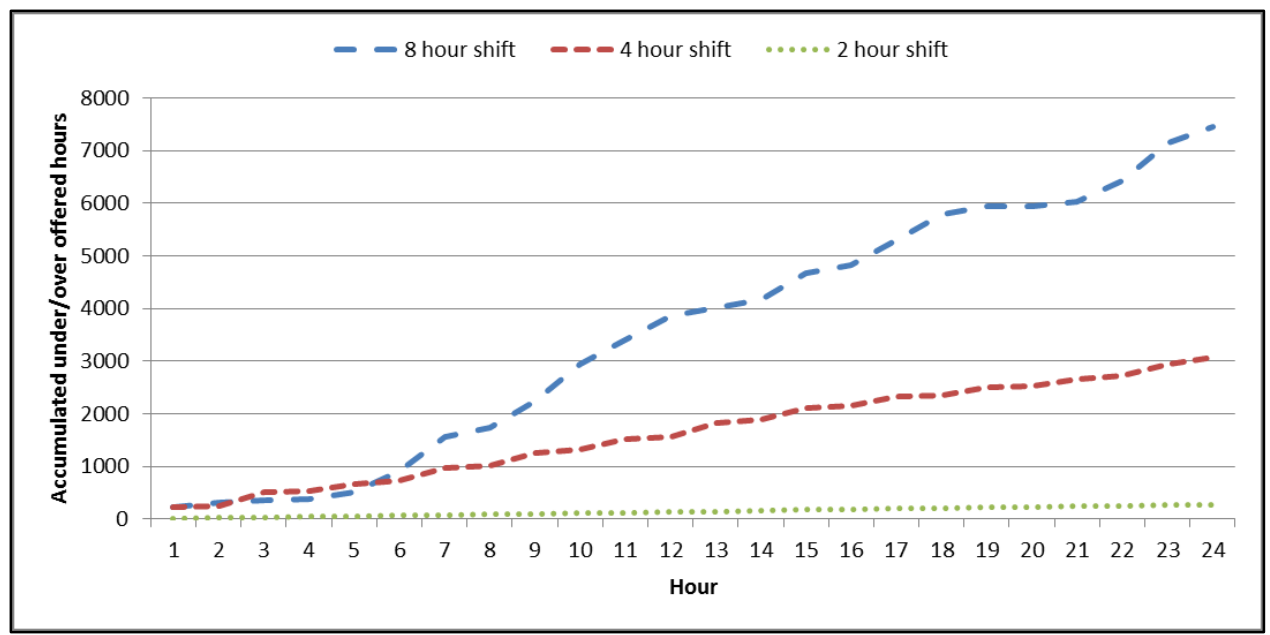

Figure 9 Accumulated under/over-offered hours during the day

The total number of hours over/under-offered during the day is more than 7,000 when applying 8-hour shifts, while in the case of 4-hour shifts this value is less than the half.

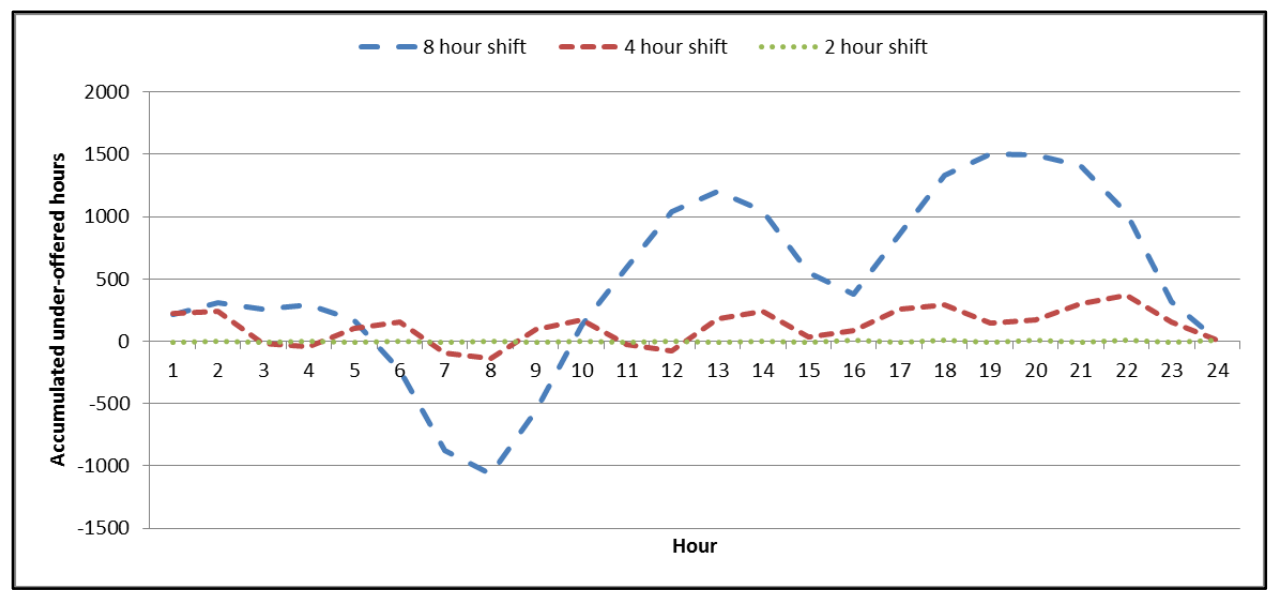

Figure 10 Number of under-offered hours during the day

The maximum accumulated deficit of taxi hours is always below 500 in the 4-hour shift, while in the 8-hour shift this value reaches an over-supply of 1,000 hours during the morning peak and an under-supply of 1.500 hours during the afternoon peak. 
From all the above, the best solution is a 2-hour shift policy, but this may not be accepted by the taxi drivers. A 4hour shift is more feasible and the results are much better than the results of an 8-hour shift policy. In order to make the 4-hour shifts more attractive to the taxi drivers, they can be grouped in pairs of shifts where the second one will start when the first one finishes, generating 8-hour shifts. This cannot be applied to all the shifts, but only to some of them. The percentage of shifts that can be grouped is calculated by measuring the area of the peaks that cannot be covered by the 4-hour horizontal line, equal to $80 \%$ in the case of Barcelona as it can be observed in Figure 11, which means that only once per week the drivers will have two 4-hour shifts instead of a 8-hour shift. For a representative day, drivers must choose one of the shift distributions presented in Table 3 . This fact can be seen positively by the drivers in the sense that they can use this "rest" period between the two 4-hour shifts for solving or attending personal issues as well as for cleaning or executing maintenance tasks in their taxi.

Table 3. Working shifts distribution

\begin{tabular}{|c|c|c|c|c|}
\hline Type $1(8$ hours $)$ & $4 \mathrm{~h}$ & $4 \mathrm{~h}$ & & $80 \%$ \\
\hline Type $2(4 \mathrm{~h}+4 \mathrm{~h})$ & $4 \mathrm{~h}$ & rest & $4 \mathrm{~h}$ & $20 \%$ \\
\hline
\end{tabular}

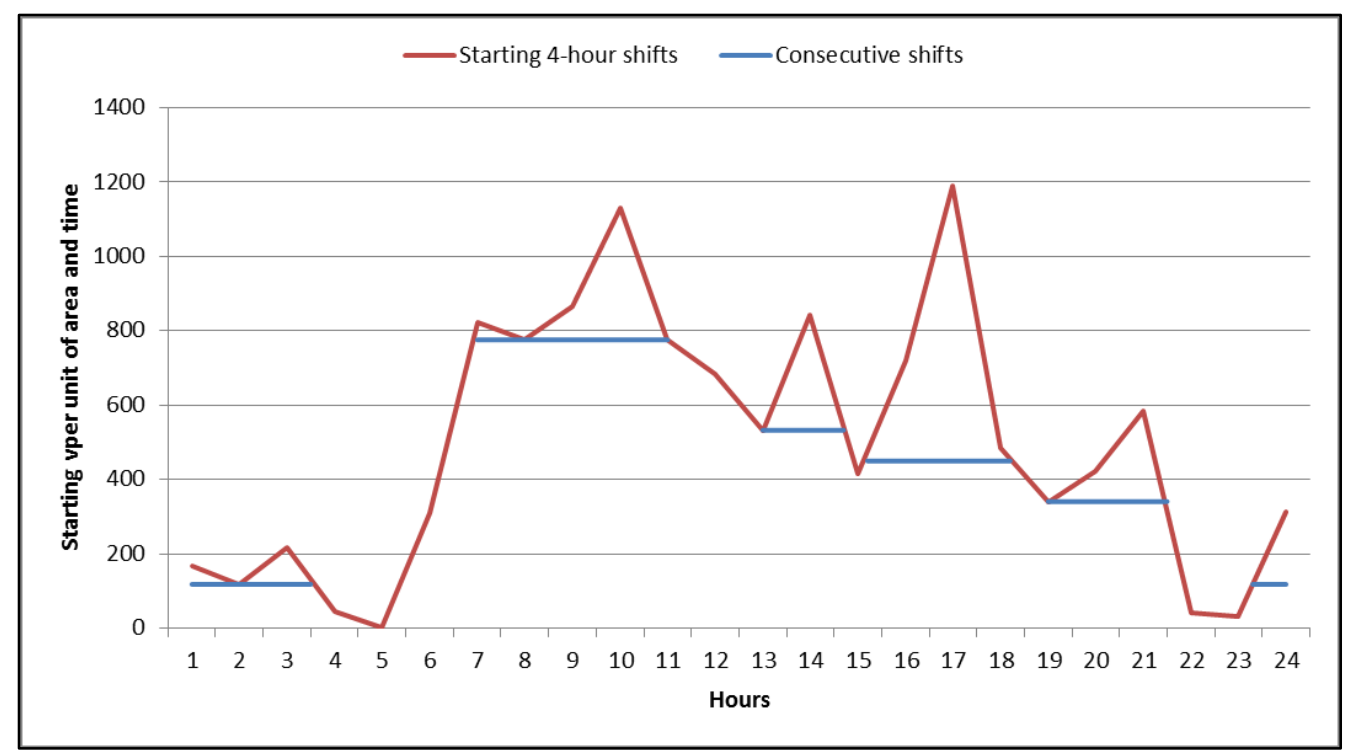

Figure 11 Grouping of pairs of 4-hour shifts

\section{Conclusions}

Two issues related to the taxi policy have been analyzed in this paper using the Barcelona taxi sector as a case study and delivering useful insights for the taxi policy makers of Barcelona, which can be put in practice in order to benefit both the taxi drivers and user as well as the citizens in general. The aggregated model has been applied to the 24-hour demand curve, presenting the optimum number of vehicle-hours for each time of day. It is concluded that different taxi operations modes are optimal for different times of the day, indicating that the decision maker may regulate the operation mode per intervals (e.g. peak and off-peak intervals), which will reduce the waiting time and unitary cost by $9-13 \%$ and $9-22 \%$ while increasing the benefit of the taxi drivers by $3 \%$ during the day and between $16 \%$ and $33 \%$ at night. Regarding the shifts policy, a 4-hour shift policy resulted to be the most feasible and efficient proposal. Any proposal of fares needs to address that the profitability of taxi drivers is achieved. The results concerning social optimum may produce a negative benefit for taxi drivers that my result in demonstrations in the streets. The impacts of the over or under supply provided in relation to the optimum levels have been identified and quantified. The total percentage of 4-hour matched shifts in the case of Barcelona is around 80\%, which means that only $20 \%$ of the shifts will have duration of 4 hours, while all other shifts will have duration of 8 hours. This means that one day each week each driver will split the 8-hour shift into two 4-hour shifts, having a rest time in between the shifts that can be used for maintenance tasks of the taxi. Regarding the fares, the introduction of elastic demand reduced significantly the social optimum to a charge of 0.67 euros per kilometer and 20 taxis per hour and $\mathrm{km}^{2}$ in Barcelona in comparison to the model with inelastic demand, which was slightly higher. 
The key question is how decision maker establishes fares using the proposed model. Firstly it should fix the number of licenses, which can be done in two different ways. The first possibility is to choose the values that maximizes the social welfare (first best solution), but it may be that in this case the taxi drivers benefits are low (or even negative), so the second option would be to choose the values that maximize the social welfare with the constraint that the benefits of the taxi drivers are not negative (zero-profit - second best solution). Since the salary of the taxi drivers is included in the functions costs as hourly cost of the provision of taxi services, the zero benefit is related to the license holder, so if this value is included in the hourly costs we would also take into account the benefit of the license holder. Secondly, the decision maker should control two things: the value of the waiting time resulting from the demand and supply matching in order to check that the level of service offered to the citizens is acceptable and the demand for taxi services resulting from the fare and the waiting time, which should also be in the desired ranges fixed by the Mobility plan of the city. If these values are not satisfactory the decision maker should modify the weights of the social welfare terms in order to reduce the waiting time (more weight in the consumer's surplus) or to increase the demand (more weight in the driver's profit).

Finally, from the application of the model to the taxi sector of the city of Barcelona, it can be concluded that the actual situation is in favor of the taxi users with regards to the number of vehicles but in favor of taxi drivers with regards to the taxi fares. Since the results obtained are based on the hypothesis that the demand is uniform, which is not the case in Barcelona (it is mostly concentrated in the city center), therefore the higher number of taxis is then in favor of the taxi drivers, concluding that the actual situation in Barcelona is mostly favoring the taxi drivers and not the taxi users. Regarding the shifts policy, a smart distribution of 4-hour shifts such the one proposed in this paper will allow for providing a better service to the taxi users while improving the working conditions of the drivers. The above conclusions prove the applicability of the proposed model and can be used by the decision makers of the city of Barcelona when establishing the fares of the taxi sector and defining the taxi shifts policy.

\section{Acknowledgements}

The authors would like to thank the Center for Innovation in Transport (CENIT) for the provision of the data. This work was supported by the Project ENTROPIA from the Spanish "Ministerio de Economía y Competitividad". Proyectos de Investigación Fundamental No Orientada. REF: TRA2012-39466-C02-01.

\section{References}

Amat i Bertran C. (2010) Anàlisi de l'eficiència del servei de taxi a Barcelona. Propostes de millora. Tesina final de Carrera. ETSECCPB Barcelona.

Arnott R., (1996) Taxi Travel Should Be Subsidized. Journal of Urban Economics 40, 316 - 333.

Brayton R.K., Director S.W., Hachtel G.D. and Vidigal L. (1979) A New Algorithm for Statistical Circuit Design Based on Quasi-Newton Methods and Function Splitting. IEEE Trans. Circuits and Systems CAS 26, 784794.

Cairns R. D., Liston-Heyes C. (1996) Competition and regulation in the taxi industry. Journal of Public Economics 59, $1-15$.

CENIT (2004) Metodologia per a l'establiment de les tarifes del taxi a l'AMB i la seva revisió. Informe final per a l'Institut Metropolità del Taxi.

CENIT (2014) Observatori del Taxi 2013. Informe final per a l’Institut Metropolità del Taxi.

Cetin, T and K. Y. Eryigit (2013); The Economic Effects of Government Regulation: Evidence from the New York Taxicab Market", Transport Policy, 25, 2013, 169-177.

Cetin, T and K. Y. Eryigit (2011); "Estimating the Effects of Entry Regulation in the Istanbul Taxicab Market", Transportation Research Part A: Policy and Practice, 45(6), 2011, 476-484. 
Chang S. K. and Chu-Hsiao Chu (2009) Taxi vacancy rate, fare and subsidy with maximum social willingnessto-pay under log-linear demand function. Transportation Research Record: Journal of the Transportation Research Board 2111, $90-99$.

Douglas G. (1972) Price Regulation and optimal service standards. Journal of Transport Economics and Policy, May, pp. 116-127.

Fernandez L. J. E., de Cea Ch. J. and Briones M. J.(2006) A diagrammatic analysis of the market for cruising taxis. Transportation Research Part E 42, 498 - 526.

Foerster J. F. And Gilbert G. (1979) Taxicab deregulation: economic consequences and regulatory choices. Transportation $8,371-378$.

Moore, AT., and Balaker, T. (2006) Do Economists Reach a Conclusion on Taxi Deregulation? Economic Journal Watch 3 (1), 109-132.

Organisation for Economic Co-operation and Development - OECD (2007). Taxi Services: Competition and Regulation. Policy Roundtables.

Salanova J. M., Estrada M., Aifadopoulou G. and Mitsakis E., (2011). "A review of the modeling of taxi services". Procedia and Social Behavioral Sciences 20: 150-161.

Salanova J. M., Estrada M., Amat C. (2014). "Aggregated modeling of urban taxi services”. Procedia - Social and Behavioral Sciences (ISSN: 18770428), 20: 352-361.

Salanova J. M. (2013). Modeling of taxi cab fleets in urban environment. PhD thesis, Polytechnic University of Catalonia, BarcelonaTECH.

Salanova J. M., Estrada M. (2016). Social optimal shifts and fares of taxi services”. Under review at Transport Policy.

Schaller B. and Gilbert G. (1995) Factors of production in a regulated industry: New York Taxi Drivers and the Price for Better Service. Transportation quarterly 49 (4), 81-91

Schaller B. (2007) Entry controls in taxi regulation: Implications of US and Canadian experience for taxi regulation and deregulation. Transport Policy 14, $490-506$.

Tong A., Zhuo W., Liucong Y., Chai C., Yanmei Y. "Matehmatical model for urban taxi subsidy scheme". International Journal of Innovative Science, Engineering and Technology, Vol. 2 Issue 11, 597 - 606.

Wong K. I., Wong S. C. and Yang H. (2001) Modeling urban taxi services in congested road networks with elastic demand. Transportation ResearchPart B 35, 819 - 842.

Wong K. I., Wong S. C. and Yang H. (2001) Modeling urban taxi services in congested road networks with elastic demand. Transportation ResearchPart B 35, 819 - 842.

Yang H., Wong S. C. and Wong K. I. (2002) Demand-supply equilibrium of taxi services in a network under competition and regulation. Transportation Research Part B 36, 799 - 819.

Yang H., Ye M., Tang W. H. and Wong S. C. (2005). Regulating taxi services in the presence of congestion externality. Transport Research A 39: 17 - 40. 